\title{
Isolation and characterization of olfactory ecto-mesenchymal stem cells from eight mammalian genera
}

Antoine D. Veron ${ }^{1,2^{*}}$, Cécile Bienboire-Frosini ${ }^{1}$, François Feron ${ }^{2,3}$, Elisa Codecasa ${ }^{1}$, Arnaud Deveze ${ }^{4,5}$, Dany Royer ${ }^{6}$, Paul Watelet ${ }^{7}$, Pietro Asproni ${ }^{1}$, Kevin Sadelli ${ }^{2}$, Camille Chabaud ${ }^{1}$, Jean-claude Stamegna ${ }^{2}$, Joël Fagot ${ }^{8}$, Michel Khrestchatisky ${ }^{2}$, Alessandro Cozzi ${ }^{1}$, François S. Roman ${ }^{2}$, Patrick Pageat ${ }^{1}$, Manuel Mengoli ${ }^{1+}$

and Stéphane D. Girard ${ }^{2,9+}$

\begin{abstract}
Background: Stem cell-based therapies are an attractive option to promote regeneration and repair defective tissues and organs. Thanks to their multipotency, high proliferation rate and the lack of major ethical limitations, "olfactory ecto-mesenchymal stem cells" (OE-MSCs) have been described as a promising candidate to treat a variety of damaged tissues. Easily accessible in the nasal cavity of most mammals, these cells are highly suitable for autologous cell-based therapies and do not face issues associated with other stem cells. However, their clinical use in humans and animals is limited due to a lack of preclinical studies on autologous transplantation and because no well-established methods currently exist to cultivate these cells. Here we evaluated the feasibility of collecting, purifying and amplifying OE-MSCs from different mammalian genera with the goal of promoting their interest in veterinary regenerative medicine. Biopsies of olfactory mucosa from eight mammalian genera (mouse, rat, rabbit, sheep, dog, horse, gray mouse lemur and macaque) were collected, using techniques derived from those previously used in humans and rats. The possibility of amplifying these cells and their stemness features and differentiation capability were then evaluated.

Results: Biopsies were successfully performed on olfactory mucosa without requiring the sacrifice of the donor animal, except mice. Cell populations were rapidly generated from olfactory mucosa explants. These cells displayed similar key features of their human counterparts: a fibroblastic morphology, a robust expression of nestin, an ability to form spheres and similar expression of surface markers (CD44, CD73). Moreover, most of them also exhibited high proliferation rates and clonogenicity with genus-specific properties. Finally, OE-MSCs also showed the ability to differentiate into mesodermal lineages.

Conclusions: This article describes for the first time how millions of OE-MSCs can be quickly and easily obtained from different mammalian genera through protocols that are well-suited for autologous transplantations. Moreover, their multipotency makes them relevant to evaluate therapeutic application in a wide variety of tissue injury models. This study paves the way for the development of new fundamental and clinical studies based on OE-MSCs transplantation and suggests their interest in veterinary medicine.
\end{abstract}

Keywords: Adult craniofacial stem cells, Dog, Ecto-mesenchymal stem cells, Horse, Non-human primate, Rabbit, Regenerative medicine, Rodent, Sheep, Veterinary medicine

\footnotetext{
* Correspondence: a.veron@group-irsea.com

'Equal contributors

'IRSEA, Research Institute in Semiochemistry and Applied Ethology, Quartier

Salignan, 84400 Apt, France

${ }^{2}$ Aix Marseille Univ, CNRS, NICN, Marseille, France

Full list of author information is available at the end of the article
} 


\section{Background}

Stem cell-based regenerative medicine is an innovative field of scientific investigation that provides reliable evidence for repairing damaged tissues and organs, both in human and veterinary medicine [1-3]. Being plastic and self-renewing, stem cells have been proposed as a potential treatment for a variety of disorders [4-9]. However, the development of such therapies remains a scientific challenge. Currently, the use of stem cells or their derivatives in human medicine is still limited to a small number of applications: hematopoietic stem cell are the only type of grafted stem cell routinely used in clinics [10]. In veterinary medicine, stem cell-based regenerative therapies are a fast growing field of research, particularly with the development of new treatments for musculoskeletal injuries $[1,2]$. However, the clinical use of stem cells in veterinary medicine is in its early stages and pre-clinical studies aimed in determining the most suitable stem cell types and modes of delivery are still required [11, 12].

Among the potential stem cell candidates for regenerative therapy, adult nasal stem cells present in the olfactory mucosa are a promising candidate both for human and veterinary medicine [13-16]. This easily accessible peripheral tissue contains highly proliferative stem cells that do not face ethical or technical issues associated with other stem cells types [17-20]. Characterized as a member of the mesenchymal stem cell (MSC) superfamily, these cells are known as "olfactory ecto-mesenchymal stem cells" (OE-MSCs) [14]. OE-MSCs are located in a permanently self-renewing nervous tissue with an ectodermal embryonic origin [21, 22] and assumed to be derived from neural crest cells, like other adult stem cells of the craniofacial area [23]. They are multipotent, providing a potential source of stem cells for treating numerous types of tissue damages [13, 14]. Moreover, human OE-MSCs can be quickly and easily propagated in sufficient numbers to meet the requirements for cell transplantation without showing tumorigenicity risks [14, 24-26]. Although the therapeutic potential of OE-MSCs has not yet been assessed in human or veterinary medicine, their therapeutic effect has been evaluated in various rodent models of tissue damage such as myocardial infarct [27], spinal cord trauma [28-30], cochlear damage [31], Parkinson's disease [32], and ischemic/hypoxic injury of the hippocampus [25, 33]. Despite the promising results reported by these studies, their clinical use in humans and animals is limited by the lack of well-established methods for the collection of these cells from living animals, and for their purification and amplification. To overcome this problem, the authors of the present study recently developed an efficient and minimally invasive procedure for autologous transplantation of OE-MSCs in rats [34]. According to this method, each animal is the donor as well as the receiver of its own cells, thereby excluding complications and side effects associated with other grafting methods.

The present study evaluated the feasibility of collecting, purifying and amplifying OE-MSCs from living animals belonging to eight genera of mammals, relevant for basic research or clinical veterinary practice. In the prospect of future autologous transplantation therapies, we also assessed OE-MSCs stemness features.

\section{Methods}

Collection of olfactory mucosa from different mammalian genera

Biopsies of nasal olfactory mucosa were obtained as previously described in humans and rats with some modifications. According to the morphology and accessibility of the nasal cavity, three protocols were used to access the olfactory mucosa. In mice, muzzle was dissected as previously described in euthanized rats [20]. For rats and gray mouse lemurs, a less invasive method, requiring nasal bone perforation at the junction with the frontal bone, was used to access the olfactory mucosa, as previously described in living rats [34]. In all other genera, biopsies were directly obtained by nasal cavity exploration with pliers, as previously described in humans $[20,35]$. Details for each genus and the strategies used for biopsies are summarized in Table 1. For all genera, the fragments of olfactory mucosa were placed, immediately after excision, in culture medium [Dulbecco's Modified Eagle's Medium/Ham's F12 (DMEM/F12) supplemented with $10 \%$ Fetal Bovine Serum (FBS), 200 units $/ \mathrm{mL}$ of penicillin, $200 \mu \mathrm{g} / \mathrm{mL}$ of streptomycin (Life Technologies), $0.25 \mu \mathrm{g} / \mathrm{ml}$ of Amphotericin B (Fungizone, Sigma/Aldrich) and $12.5 \mu \mathrm{g} / \mathrm{ml}$ of Plasmocin Treatment (InvioGen)]. For horse cells, the culture medium was supplemented with $1 \mu \mathrm{g} / \mathrm{ml}$ of Ketoconazole (Sigma/Aldrich) to prevent fungal contamination due to stabling. Then, the pieces of olfactory mucosa placed in the culture medium were stored in a refrigerated container until processing.

Anesthesia and surgical procedures were performed according to the European law on Animal Care Guidelines and the Animal Care Committee of Aix-Marseille University and Ethic Committee of IRSEA (C2EA125) approved our protocols.

\section{Isolation and expansion of OE-MSCs}

Cultures of OE-MSCs were carried out as previously described by the authors [34]. Following biopsy, pieces of olfactory mucosa were washed twice in DMEM/ F12 medium. The biopsies were then dissected into small pieces using 25-gauge needles $\left(<1 \mathrm{~mm}^{2}\right)$. Each explant was plated on a $2 \mathrm{~cm}^{2}$ culture well coated with poly-Llysine $\left(5 \mu \mathrm{g} / \mathrm{cm}^{2}\right.$ in sterile water, Sigma-Aldrich). Except for rodents, the mucosal pieces were covered with a 


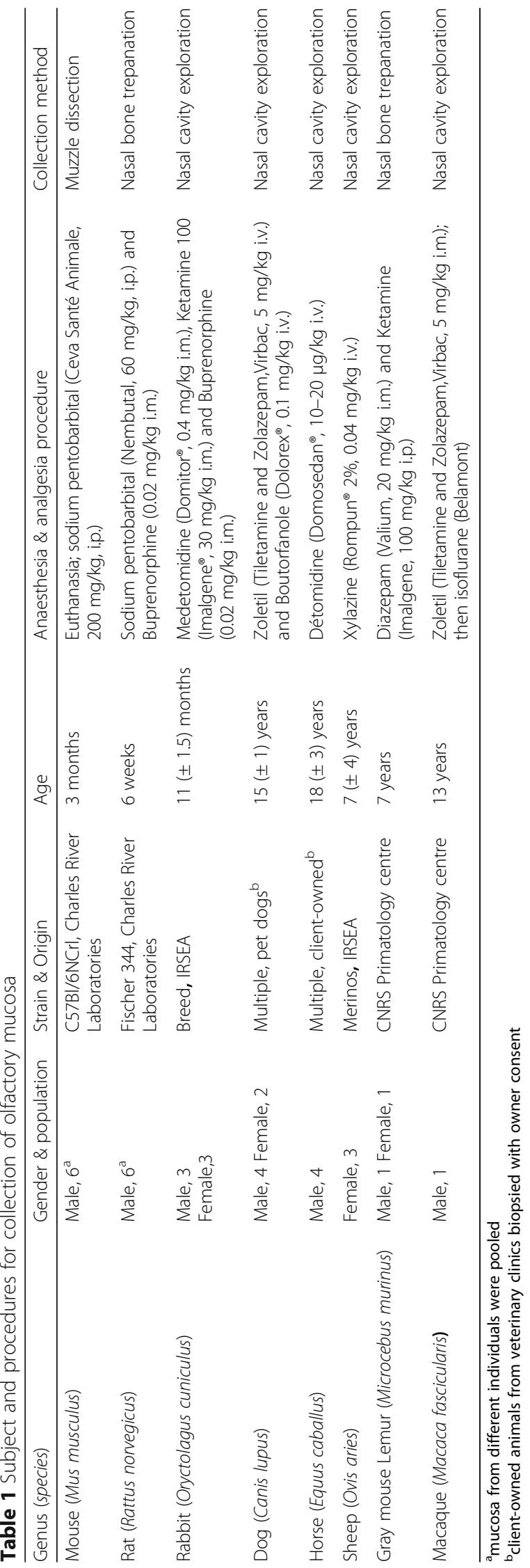


sterile glass coverslip to facilitate and accelerate the adhesion of the explants at the bottom of the culture wells. The wells were filled with $250 \mu \mathrm{l}$ of the culture medium described above. One week later, concentrations of antibiotics were reduced (100 units/mL of penicillin and to $100 \mu \mathrm{g} / \mathrm{mL}$ of streptomycin), Amphotericin B and Ketoconazole were removed and Plasmocin Treatment was replaced by $1.25 \mu \mathrm{g} / \mathrm{ml}$ Plasmocin Prophylactic (InvivoGen). This medium is referred as growth medium throughout the manuscript. Culture medium was gently renewed every 2 to 3 days. After an additional week, the cells began to grow out of the explants and invaded the culture dish. When confluency was reached, the cells were detached using a trypsin-EDTA solution $(0.05 \%$, Life Technologies), pooled and centrifuged at $300 \mathrm{x}$ g for 5 min and replated without exceeding a 1:3 cell split ratio. When several individuals of a species were biopsied, cells from different cultures were compared.

\section{Generation of spheres}

For generating spheres, cells were counted in duplicate using an automated counter (Scepter, Millipore) and plated at a density ranging from $15,000 \mathrm{cells} / \mathrm{cm}^{2}$ to 30,000 cells $/ \mathrm{cm}^{2}$ (rabbit: 15,000 cells $/ \mathrm{cm}^{2}$; mouse \& rat: 30,000 cells $/ \mathrm{cm}^{2}$; all other genera: 20,000 cells $/ \mathrm{cm}^{2}$ ), into poly-L-lysine coated dishes $\left(5 \mu \mathrm{g} / \mathrm{cm}^{2}\right)$ and fed with serum-free DMEM/ F12 culture medium supplemented with insulin, transferrin, selenium (ITS-X, 1\% Life Technologies), Epidermal Growth Factor (EGF, $50 \mathrm{ng} / \mathrm{mL}$; R\&D Systems) and Fibroblast Growth Factor 2 (FGF2, $50 \mathrm{ng} / \mathrm{mL}$; R\&D Systems). This culture medium was changed every two days. After 10 days of treatment, spheres were harvested by gently shaking the medium and pooled in one culture well $\left(2 \mathrm{~cm}^{2}\right)$ for imaging.

\section{Immunocytochemistry}

Immunocytochemistry was carried out to assess expression of nestin protein, known to be strongly expressed in OE-MSCs [14, 34] and neural proteins GFAP and MAP2. OE-MSCs (passage 6) were plated on glass coverslips at a density of 15,000 cells per $\mathrm{cm}^{2}$ in growth medium for approximately $48 \mathrm{~h}$. The cells were then fixed in a paraformaldehyde solution (4\%, Antigenfix, MM France) for $15 \mathrm{~min}$ and incubated for $1 \mathrm{~h}$ at RT with blocking solution (3\% bovine serum albumin, 5\% goat serum and $0.1 \%$ Triton X-100, Sigma Aldrich) in phosphate-buffered saline (PBS) solution. Glass coverslips were then incubated for 90 min at RT with the appropriate primary antibody diluted in the blocking solution (Table 2). For nestin detection, mouse monoclonal anti-nestin (Abcys) was used for rodent and rabbit polyclonal anti-nestin (Abcam) for all other studied genera. The cells were then rinsed 3 times in PBS and incubated for $60 \mathrm{~min}$ with the appropriate polyclonal
Table 2 Antibodies used for immunochemistry \& flow cytometry

\begin{tabular}{llllll}
\hline Target & Host & Supplier & Reference & Dilution & $\begin{array}{l}\text { Secondary } \\
\text { antibody }\end{array}$ \\
\hline Nestin & Mouse & Abcys & VMA353 & $1: 250$ & Alexa Fluor 488 \\
Nestin & Rabbit & Abcam & ab7659 & $1: 200$ & Alexa Fluor 488 \\
Tenomodulin & Rabbit & Abcam & ab81328 & $1: 500$ & Alexa Fluor 488 \\
Scleraxis & Rabbit & Abcam & ab58655 & $1: 500$ & Alexa Fluor 488 \\
GFAP & Chicken & Abcam & ab4674 & $1: 500$ & Alexa Fluor 488 \\
MAP2 & Chicken & Abcam & ab5392 & $1: 500$ & Alexa Fluor 488 \\
CD34 & Rabbit & Abcam & ab150060 & $1: 50$ & Alexa Fluor 488 \\
CD44 & Rabbit & Abcam & ab157107 & $1: 50$ & Alexa Fluor 488 \\
CD73 & Rabbit & Abcam & ab175396 & $1: 110$ & Alexa Fluor 488 \\
Rabbit lgG & Rabbit & Abcam & ab171870 & $1: 50$ & Alexa Fluor 488 \\
\hline
\end{tabular}

GFAP Glial Fibrillary Acidic Protein, MAP2 Microtubule-associated protein 2

secondary antibody (1:500, Jackson ImmunoResearch, Table 2). After several washes in PBS, cells were counterstained with $0.5 \mu \mathrm{g} / \mathrm{mL}$ Hoechst blue $(33,258$, SigmaAldrich) for $10 \mathrm{~min}$ and mounted with anti-fading medium (ProLong Diamond; Life Technologies). Negative control conditions were carried out by omitting the primary antibody. Pictures were acquired with an inverted microscope (Axio Imager, Carl Zeiss microscopy, Germany) and negative controls were used to adjust image acquisition parameters.

\section{Flow cytometry analysis}

Using flow cytometry, we analyzed expression of 3 surface markers. Two of them (CD44 and CD73) are known to be strongly expressed in human OE-MSCs [14] while the third one, CD34, is not expressed. Cells were washed twice in PBS and then harvested using TrypLE ${ }^{\mathrm{Tw}}$ Select Enzyme (Life Technologies). Then, the cells were centrifuged (300 x g, $5 \mathrm{~min}$ ), resuspended in cold blocking solution (10\% FBS in PBS) and centrifuged again. Cells were paraformaldehyde-fixed for $15 \mathrm{~min}$ RT (4\%, Antigenfix), washed twice in blocking solution and permeabilized in cold methanol $\left(90 \%,-20{ }^{\circ} \mathrm{C}\right) 30 \mathrm{~min}$ at $4{ }^{\circ} \mathrm{C}$, before being washed twice in blocking solution. Cells were then incubated 20 min RT with primary antibodies against CD34, CD44 or CD73 (Table 2) diluted in blocking solution or incubated with the corresponding isotype control (rabbit IgG, Table 2) at the same concentration, as a negative control. Cells were then washed 3 times by centrifugation $(600 \mathrm{x} \mathrm{g}, 5 \mathrm{~min})$ and incubated 20 min RT in the absence of light with the corresponding secondary antibody diluted in blocking solution (Table 2). After three washes, cells were immediately processed for flow cytometric analysis. Acquisitions were performed on a FACSCanto II flow cytometer (BD Biosciences) using BDFACSDiva software. At least 10,000 events were recorded for each analysis and measures 
were performed in duplicate. Percentages are presented after the subtraction of isotype background and refer to the total living population analyzed.

\section{Clonal efficiency assay}

The assay was carried out by plating OE-MSCs (passage 7) from one representative culture per genus in 6-well plates at a density ranging from 10 to 320 cells/well in triplicate by using a 1:2 serial dilution in growth medium. After plating, the dishes were placed in an incubator $\left(37^{\circ} \mathrm{C}, 5 \%\right.$ $\mathrm{CO} 2$ ) and left untouched for 7 days before being paraformaldehyde-fixed (4\%, Antigenfix) during $15 \mathrm{~min}$ at room temperature (RT). Colonies were stained for $15 \mathrm{~min}$ using crystal violet and then manually counted. For each sample, clonal efficiency (\% of clonogenicity) was calculated as follows: (mean number of colonies/total number of seeded cells $) \times 100$. When too many colonies overlapped, counting was not performed.

\section{In vitro proliferation assay}

The assay was performed on OE-MSCs for each studied genus, 2 months (10 passages) and 3 months (20 passages) after the initial plating. Cells from one representative culture per genus were seeded at a density of 200 cells $/ \mathrm{cm}^{2}$ in 24-well plates in triplicate in growth medium, during $8,24,48,72$ or $96 \mathrm{~h}$. After being paraformaldehyde-fixed (4\%, Antigenfix) for $15 \mathrm{~min}$ at RT and stained with Hoechst blue $(0.5 \mu \mathrm{g} / \mathrm{ml}$, SigmaAldrich), the cells were counted for each of the 6 tested conditions, using an inverted microscope (Zeiss microscopy) and a computer procedure (ImageJ). The population doubling-time was calculated using "DoublingTime.com" (Roth V. 2006).

\section{In vitro mesodermal differentiation assays}

Human OE-MSCs have been previously described to be able to differentiate in vitro into different types of mesodermal cells (Murrel et al., 2005; Delorme et al., 2010). These characteristics in OE-MSCs from rat, rabbit, dog and horse were assessed. For osteogenic and chondrogenic differentiation, olfactory stem cells were grown using same techniques as previously described [14]. To evaluate osteogenic differentiation, cells cultures were fixed in a paraformaldehyde solution (4\%) for $15 \mathrm{~min}$ and stained with von Kossa (Bio-Optica) or Alizarin Red stain (ScienCell), according to manufacturers' instructions. For chondrogenic differentiation, cells were grown in pellets and fixed in 10\% buffered formalin ( $\mathrm{pH} 7.4$ ), routinely processed and paraffin-embedded. Four $\mu \mathrm{m}$ thick sections were cut and stained with Toluidine blue (Diapath) or Alcian blue (Bio-Optica) according to instructions.

For tenogenic differentiation, we adapted different protocols used for MSC differentiation. Thus, 30.000
OE-MSCs were grown on a $5 \mu \mathrm{g} / \mathrm{cm}^{2}$ collagen-I matrix (Sigma/Aldrich) in DMEM without FBS, $50 \mathrm{ng} / \mathrm{ml} \mathrm{GDF-}$ 5 (R\&D Systems), $50 \mathrm{ng} / \mathrm{ml} \mathrm{GDF-7} \mathrm{(R \& D} \mathrm{Systems)} \mathrm{and}$ $20 \mathrm{ng} / \mathrm{ml}$ TGF-B3 (R\&D Systems) for 7 days [36-38]. To evaluate tenogenic differentiation, cells were fixed as previously described and immunochemistry against Tenomodulin and Scleraxis proteins carried out using the same procedure described above, with the appropriate antibodies (see Table 2).

\section{Results \\ Biopsies of olfactory mucosa on living animals}

Olfactory mucosa biopsies were successfully performed on living animals from all genera except mice, with some differences in collection and culture techniques (Table 1). Biopsied animals under anesthesia could recover within a few hours after surgery without any sign of pain or unwanted side effects. The only undesirable effect observed in all studied genera was nasal bleeding immediately following the biopsies, which was rapidly suppressed by applying a sterile gauze in the nose or on the bone window.

\section{Isolation and amplification of cells with fibroblastic morphology from olfactory mucosa biopsies}

One to two weeks after biopsy, adherent cells with heterogeneous morphologies from each genus began to grow out of the explants and invaded the culture dish. After 2 passages, cultures became more homogenous and cells exhibited a fibroblastic morphology (Fig. 1a). Cells from mouse showed morphological changes with increasing passages or dilution associated with a difficulty in amplifying them. A vulnerability to dilution was also observed for all genera during the first steps of amplification, with a decrease in cell proliferation if split ratio exceeded 1:2 (data not shown).

\section{OE-MSCs from different mammalian genera display features of stemness}

After amplification, two stemness and immaturity features that were previously described in human $\mathrm{OE}$ MSCs were assessed: the ability to give rise to spheres and the expression of nestin. When grown under specific appropriate culture conditions, OE-MSCs from all genera could generate spheres (Fig. 1b).

For each genus, the entire population of OE-MSCs expressed the nestin protein, a prominent marker of immaturity, with similar intensities of expression across all genera (Fig. 1c).

Finally, OE-MSCs were successfully transfected to express GFP, a prerequisite for transplantation studies involving cell tracking (data not shown). 

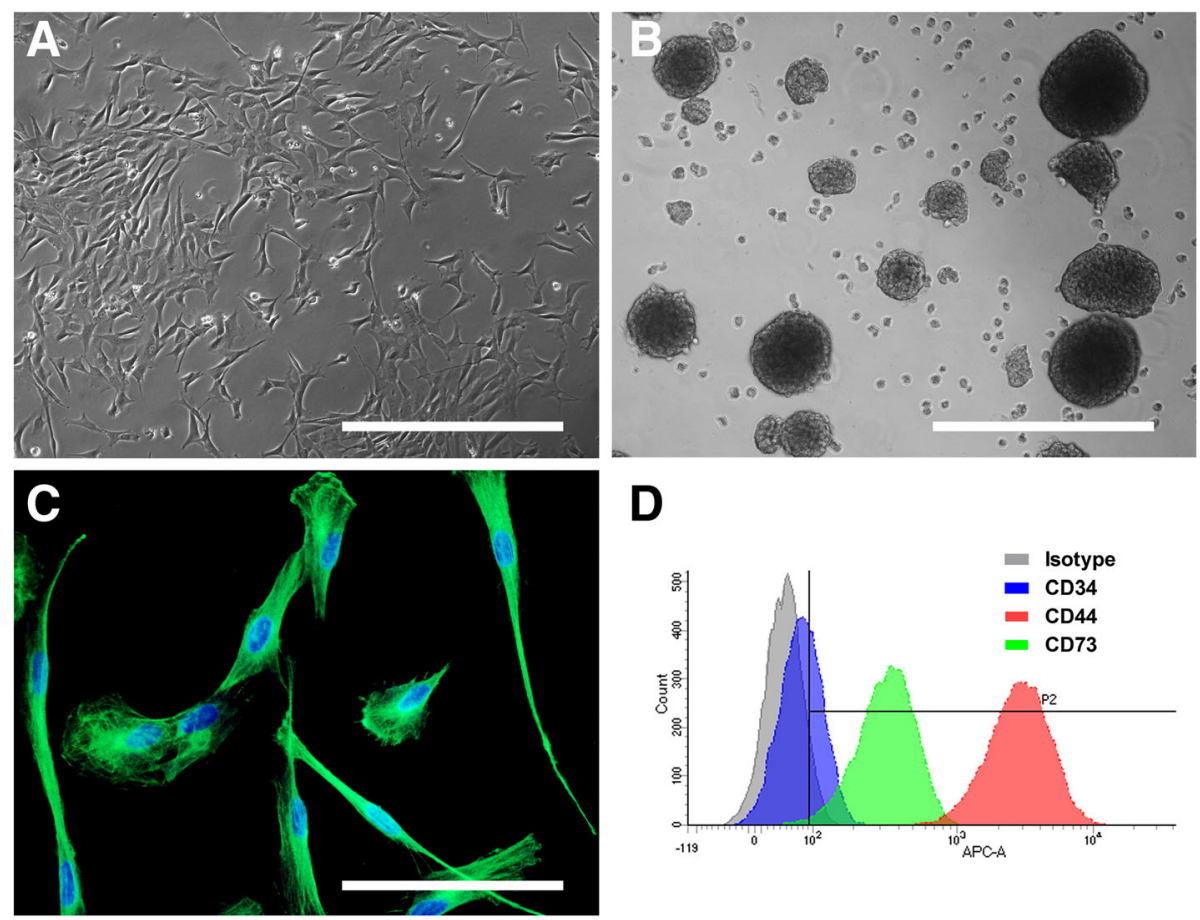

D

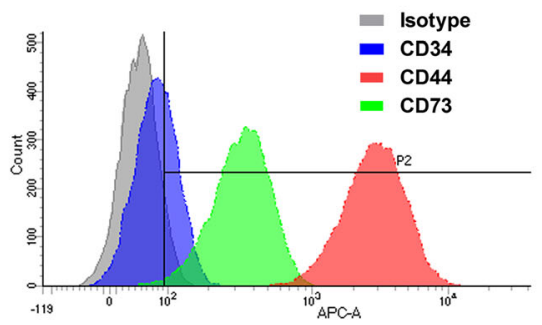

Fig. 1 Morphology and stemness features of OE-MSCs from different mammalian genera. After 4 weeks in growth culture medium, olfactory mucosa explants formed homogeneous populations of adherent and highly proliferative cells exhibiting a mesenchymal-like fibroblastic morphology: examples of sheep (a). When grown under appropriate culture conditions, OE-MSCs could generate spheres: examples of rabbit (b). After seven passages, cells express the nestin protein (in green, (c) example of rabbit), a prominent marker of immaturity. OE-MSCs were immunostained with 3 surface markers, quantified using a flow cytometer and expression level compared to isotype: example of macaque (d). Each image is representative of multiple independent cultures of each species. Scale bar: $200 \mu \mathrm{m}(\mathbf{a} \& \mathbf{b}), 100 \mu \mathrm{m}(\mathbf{c})$

OE-MSCs from different mammalian genera display similar expression of mesenchymal stem cell surface markers

We analyzed expression of 3 surface markers by flow cytometry. In each genus studied, CD34 expression was extremely low or undetectable with a percentage of cells expressing this marker inferior to 10 (Fig. $1 \mathrm{~d}$ and Table 3). CD44 was highly and homogeneously expressed in OE-MSCs from all genera with a percentage of cells expressing this marker superior to 90 except in horse (68\%). Expression of CD73 marker was more variable in the different genera. While percentage of cells

Table 3 Analysis of surface markers expression by flow cytometry

\begin{tabular}{llll}
\hline \multicolumn{4}{c}{$\begin{array}{l}\text { \% cells expressing markers } \\
\text { (mean } \pm \text { SEM) }\end{array}$} \\
\hline Genus & CD34 & CD44 & CD73 \\
Rat & $4.7 \pm 0.6$ & $98.6 \pm 0.0$ & $56.7 \pm 11.0$ \\
Rabbit & $0.7 \pm 0.4$ & $91.2 \pm 1.0$ & $22.0 \pm 1.6$ \\
Sheep & $5.0 \pm 0.3$ & $98.4 \pm 0.0$ & $64.3 \pm 0.1$ \\
Dog & $9.2 \pm 2.2$ & $96.1 \pm 0.0$ & $58.7 \pm 15.2$ \\
Horse & $2.4 \pm 1.1$ & $68.6 \pm 5.8$ & $5.5 \pm 3.1$ \\
Gray mouse lemur & $-1.0 \pm 1.1$ & $95.4 \pm 0.0$ & $93.6 \pm 0.0$ \\
Macaque & $1.7 \pm 1.2$ & $95.6 \pm 1.0$ & $73.9 \pm 4.4$ \\
\hline
\end{tabular}

expressing this marker is superior to $50 \%$ in cell population from rat, sheep, dog, gray mouse lemur and macaque, CD73 expression was low in OE-MSCs from rabbit (22\%) and extremely low in horse cells (5.5\%).

\section{High clonal efficiency and proliferation rate of OE-MSCs}

Evaluation of clonal efficiency after seeding of the cells at low density indicated that a high percentage of $\mathrm{OE}$ MSCs from all studied genera could give rise to colonies after 7 days in culture, except mice OE-MSCs which were unable to generate new clonal populations (Fig. 2a). The percentage of OE-MSCs generating new colonies after seven passages ranged between $50 \%$ and $70 \%$ in rat, dog, horse, sheep, gray mouse lemur and macaque. Rabbit cells displayed a lower clonal efficiency (20\%) in comparison to their outstanding proliferation rate (Fig. 2b). Assessment of the population doubling-time in short-term (passage 10, 2 months of culture) and longterm (passage 20, 3 months of culture) passages revealed that most OE-MSCs are quickly dividing cells. As shown in Fig. 2b, cells from all genera, except those derived from gray mouse lemur olfactory mucosa, displayed a doublingtime ranging from 20 and $40 \mathrm{~h}$ after 10 passages. Except for the sheep and gray mouse lemur, the doubling-time 


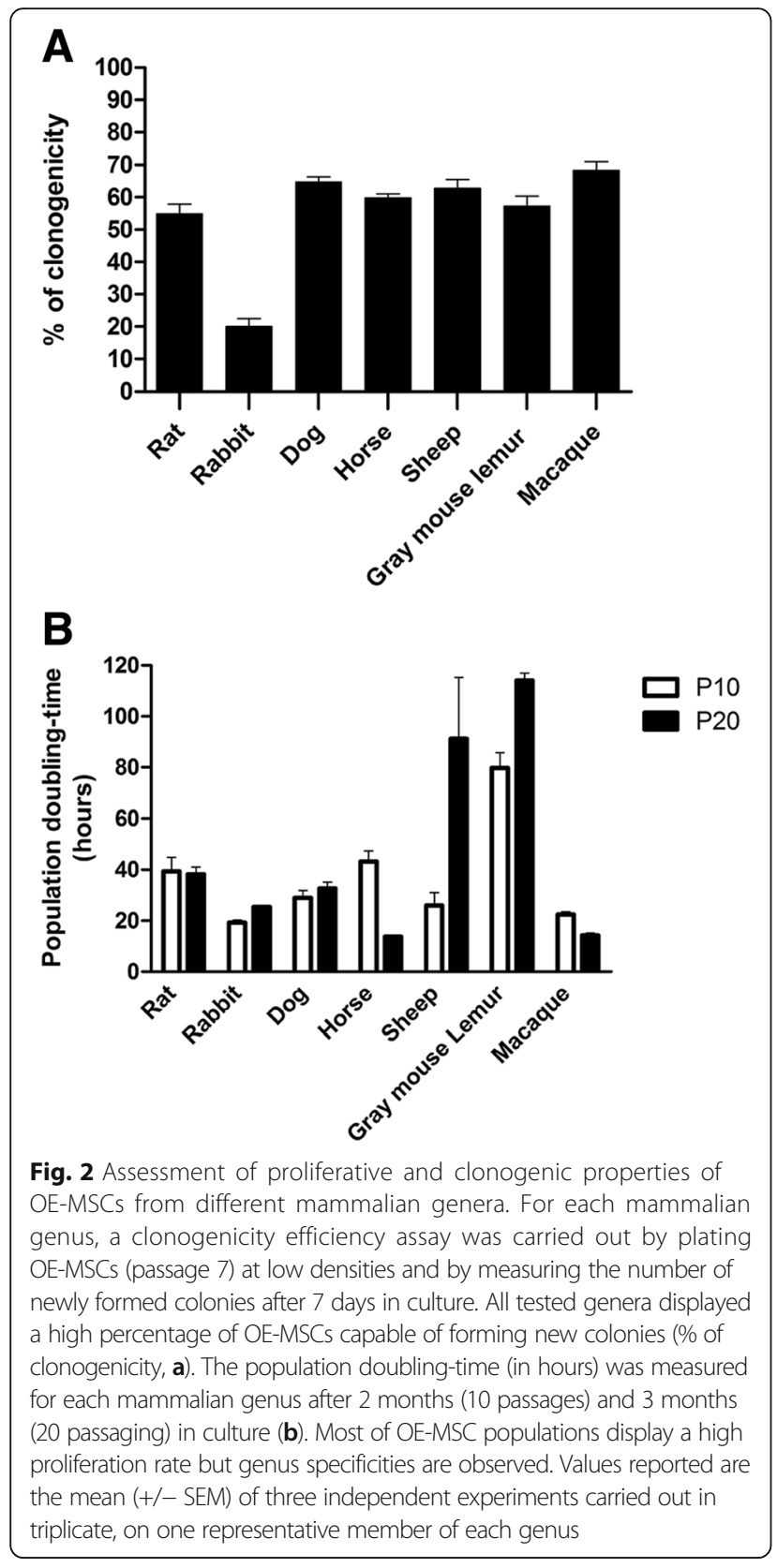

remained stable after 20 passages and even decreased in horse and macaque cells.

In vitro assessment of differentiation abilities of OE-MSCs Prior to any differentiation, we observed that cells from four studied genera (rat, rabbit, dog and horse) expressed neural proteins GFAP (Fig. 3a) and MAP2 (Fig. 3b) at a basal state. Subsequently, differentiation assays of these cells into cells of the mesodermal lineage were performed. We found they could be induced to express bio-chemical features specific to osteoblasts (Fig. 3c \& d), chondroblasts (Fig. 3e \& f) and tenoblasts (Fig. $3 g \&$ h). Detailed results of differentiation are reported in Table 4. Osteoblast differentiation was ineffective in rat OE-MSCs but cells from the other studied genera were reactive for Red Alizarin and Von kossa stainings (Fig. 3c \& d). Only horse and rat OE-MSCs were reactive for both Toluidine Blue (E) and Alcian Blue (F) stainings after chondrogenic differentiation. Dog OE-MSCs were reactive only for Alcian Blue while cells from rabbit did not display any sign of differentiation. Tenogenic differentiation was positive for all the four genera studied and all the cells expressed both scleraxis protein and Tenomodulin.

\section{Discussion}

The present study showed for the first time that OEMSCs can be extracted from eight different mammalian genera and amplified to get tens million cells in few weeks. Cells displayed similar features to their human counterparts: a fibroblastic morphology, a robust expression of nestin, an ability to form spheres, a similar expression of surface markers (CD44, CD73), a high proliferation rate and an ability to be induced into cells of the mesodermal lineages; although some genus-specific properties were observed. These sampling and amplification techniques may permit autologous grafts for preclinical studies or clinical use in veterinary medicine in a wide variety of models.

Unlike previous methods used for the collection of rat olfactory mucosa, for the purposes of this study techniques were developed to harvest the appropriate tissue without sacrificing the donor animal [20] (Table 1). It is important to note that, except for occasional bleeding that can be prevented, no visible side effects were observed when a postoperative antibiotic treatment was applied. These results confirm those previously obtained in rats showing no disorder of the sense of smell after biopsy [34]. Among the eight tested genera, only the mouse olfactory mucosa was not collected on living animals. Surgery was considered too invasive for such a small nasal cavity and, accordingly, only syngeneic or allogeneic grafts can be considered for use in this genus.

\section{OE-MSCs: Similar characteristics shared by the different genera}

Despite some differences between genera, the results indicated that the various mammalian OE-MSCs displayed similar characteristics to those previously described in their human counterparts [14]. Noticeably, these methods were successful in obtaining many highly proliferative cells. Interestingly, though it is not possible to ascertain the absolute purity of stem cells and exclude potential contamination with other cell types, such as the olfactory ensheathing cells, the populations of OEMSCs were highly homogeneous, when comparing cell morphology, expression of nestin and surface markers 

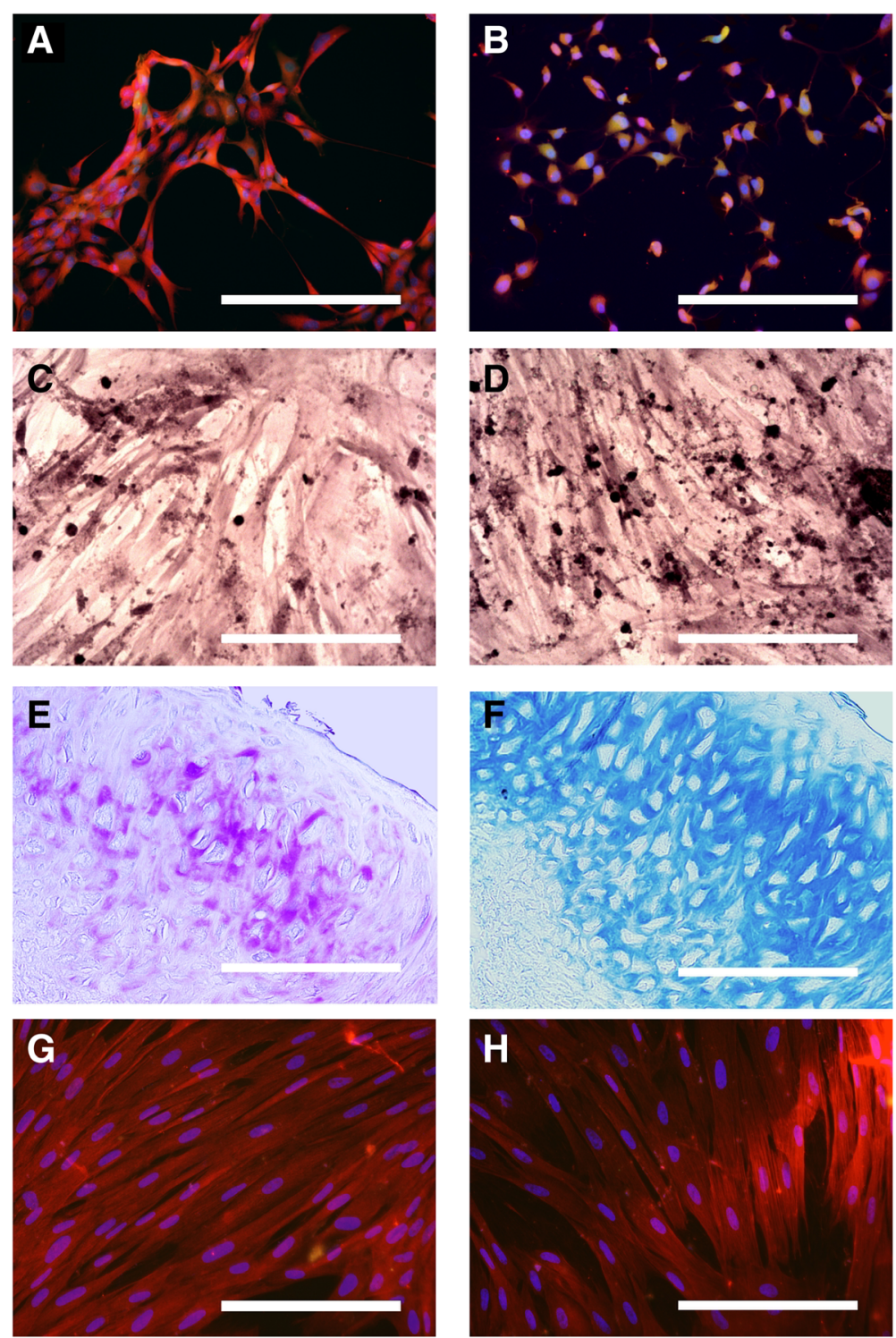

Fig. 3 Assessment of neural and mesodermal differentiation abilities of OE-MSCs in vitro. Multipotency was assessed in OE-MSCs from rat, rabbit, dog and horse. Expression of the neural proteins GFAP (a) and MAP2 (b) in red in undifferentiated rat OE-MSCs. Bone differentiation was assessed using Red Alizarin (c) and Von kossa (d) stainings. Dog OE-MSCs were positively labeled in red (c) and in black (d) using these procedures. Chondrogenic differentiation was assessed using Toluidine Blue $(\mathbf{e})$ and Alcian Blue $(\mathbf{f})$ stainings. Horse OE-MSCs were positively labeled in purple $(\mathbf{e})$ and in blue (f) using these procedures. Expression of the tenocytic markers Scleraxis protein $\mathbf{( g )}$ and Tenomodulin $(\mathbf{h})$ in red in rabbit OE-MSCs. Each image is representative of multiple independent cultures of each species. Scale bar: $200 \mu \mathrm{m}$

Table 4 In vitro assessment of mesodermal differentiation of OE-MSCS

\begin{tabular}{llllll}
\hline Tissue & Antibody / Staining & Rat & Rabbit & Dog & Horse \\
\hline Bone & Von Kossa & - & - & + & + \\
& Alizarin Red & - & + & + & + \\
Cartilage & Alcian Blue & + & - & + & + \\
& Toluidine Blue & + & - & - & + \\
Tendon & Scleraxis & + & + & + & + \\
& Tenomodulin & + & + & + & + \\
\hline
\end{tabular}

CD34 and CD44 according to previous studies in human and rat $[14,20,34]$. While the expression of CD34 and CD44 in cells from all genera was similar with the data from human OE-MSCs, we observed higher variability for CD73. First, this marker could not be detected at significant levels in horse OE-MSCs. Although we could not exclude that the antibody used was not able to recognize the horse protein, this observation agrees with other research groups who could not detect CD73, using multiples antibodies, in different horse MSC subtypes that normally express this marker in humans and 
rodents [39-41]. While the same technical issues may happen with cells from rabbit, CD73 is not, weakly or highly expressed in rabbit MSCs according to three different studies [42-44]. However, our results confirm the data of another research team which observed a similar percentage of positive cells (28\%) [45]. In addition to the expression of these markers, the ability to generate spheres, the strong mitotic activity that remained high in most cases after 20 passages, and the high clonal efficiency rate, serve as indisputable proofs of the stemness features of these cells.

For unknown reasons, mouse olfactory stem cells were the most difficult to grow and amplify and were not tested for following evaluations. Accordingly, in addition to the complexity of collecting olfactory mucosa biopsies in living mice, autologous transplantations appear highly difficult in this genus.

\section{OE-MSCs: Interesting in vitro characteristics for in vivo applications}

Compared to human OE-MSCs [14], cells from different genera displayed similar clonal ability (with the exception of rabbit cells), and shorter doubling-times, probably due to the study's improved culturing techniques. Moreover, this study opens perspectives for future researches by demonstrating that these cells can be easily transfected to express GFP (data not shown). Thus, stem cells can be tracked in vivo after grafting to observe their differentiation, integration and interaction with the surrounding environment.

These perspectives are enhanced by the multipotency of OE-MSCs, an ability we evaluated in four species relevant for basic research or clinical veterinary practice While stem cells from rat, rabbit, dog and horse express at basal states two markers of neural cells, GFAP and MAP2, certainly due to their origin from an ectodermic tissue [21, 22], they could also differentiate into cells of mesodermal lineage. Overall, we confirmed the results of other studies evaluating differentiation abilities of OEMSCs [13, 14, 46, 47].

Cells from these four genera could be induced in tenoblasts-like cells but the expression of bio-chemical features specific to osteoblasts and chondroblasts depend on genera. This variability may be potentially explained by inter-species sequence differences of differentiating factors and their receptors that can induce a loss of differentiation efficiency for some studied genera.

\section{OE-MSCs: An interesting tool for veterinary medicine}

Among all stem cell candidates for regenerative therapies, those originating from bone marrow or adipose tissue are the most extensively studied $[48,49]$. A recent study demonstrated the advantages but also the limitations associated with these particular types of stem cells
[2]. Although bone marrow is known for containing a high number of MSCs, the collection procedure is complex, painful and may induce a non-negligible risk of infection or hemorrhage [50,51]. Comparatively, collection of adipose tissue is less invasive and provides MSCs displaying similar properties [3, 52]. However, the quality of fat-derived stem cells seems subject specific [53-55], which limit their interest for cellular therapies.

The OE-MSCs presented in the current study are abundant in the olfactory mucosa and their proliferative abilities allow for rapid propagation [24, 47].

The therapeutic potential of OE-MSCs has been positively evaluated in various rodent models of tissue damage without inducing tumors, supporting the need for further assessment in clinical applications [25, 28, 32, 56]. In fundamental research, stem cells are commonly used in mice, rats, rabbits, gray mouse lemurs and macaques. Several studies have reported various applications for injured [9] or degenerative central nervous systems [4], orthopedic problems [57], cartilage defects [58], tendon-tobone healing [59], and skeletal [60] and cardiac [7] muscle engineering and OE-MSCs, thanks to their multipotency, may be promising to treat such defects.

Moreover, cell-based treatments in large animal models are emerging $[1,2,12]$. Due to their anatomical, physiological and genetic similarities to humans, domestic animals or non-human primate represent a step towards clinical applications. Gray mouse lemurs and dogs are now commonly recognized as reliable natural models of Alzheimer-like diseases [61-64]. Osteoarticular diseases also play a major role in veterinary medicine, especially in dogs and horses $[65,66]$. Techniques presented here opens perspectives for future researches on these natural models.

While the present study focuses on OE-MSCs, it can be pointed out that the olfactory mucosa may also be used as a source of another cell type of great interest for regenerative medicine, namely the olfactory ensheathing cells $[47,67,68]$. Olfactory ensheathing cells are central glia sharing common properties with immature Schwann cells [69]. They have been shown to promote axonal regeneration in the CNS $[68,70]$ and reduce neuroinflammation [71] after being transplanted alone or in combination with stem cells.

\section{Conclusion}

The current study confirms that OE-MSCs can be easily harvested from olfactory mucosa of most mammalian genera for use in autologous transplantation without any damaging side effects. Reported techniques of biopsy and culture can be used to obtain millions of nasal olfactory stem cells in a short time. Their outstanding ability to proliferate and stemness characteristics, associated with abilities to generate cells from different lineages, 
make these multipotent stem cells suitable tools for regenerative medicine. This study paves the way for i) the development of fundamental research on a wide variety of models of tissue injuries and ii) clinical trials to evaluate the therapeutic benefit of OE-MSCs. For domestic and/or companion animals, the development of such therapies shows great promise as it will positively impact the lives of veterinary patients, while promoting human applications.

\section{Abbreviation}

GFP: Green Fluorescent Protein; MSC: Mesenchymal stem cell; OE-MSC: Olfactory ecto-mesenchymal stem cell

\section{Acknowledgments \\ The authors thank Dr. Frederic Levy and Dr. Isabelle Virard for kindly giving us access to sheep, and mice, respectively, and the veterinarians Dr. Ivan Balansard and Dr. Stefano Disperati for their help in the collection of olfactory mucosa from primates and dogs, respectively. HSC1-GiP EiP-GFP plasmid was kindly given by Sylvie Rival-Gervier. We also thank Pr. Alan Mackay-Sim for providing one macaque and Eve Landen for proofreading the manuscript.}

\section{Funding}

This work was supported in part by grants from the French "Institut de Recherche sur la Moelle Epinière et l'encéphale" (IRME). We acknowledge support from the "Fonds Européen de Développement Régional" FEDER in PACA region. ADV was the recipient of a "Convention Industrielle de Formation par la Recherche" (CIFRE) fellowship from the "Association Nationale de la Recherche et de la Technologie" (ANRT) and IRSEA.

The funders had no role in the study design, data collection or analysis, nor in the preparation of the manuscript or the decision to publish.

\section{Availability of data and materials}

The datasets supporting the conclusions of this article are included within the article.

\section{Authors' contributions}

ADV carried out rodent and rabbit biopsies, participated in the conception and design of the study, performed culture and cellular biology experiments and drafted the manuscript. CBF participated in the design of the study, coordinated the biopsies from rabbits, horses, and dogs, and helped to draft the manuscript. FF coordinated sampling and culture of olfactory mucosa from primates, helped in analysis and interpretation of data and manuscript revision. EC and PA carried out biopsies from rabbits and sheeps. AD carried out biopsies on primates, DR on dogs, and PW on horses. FSR coordinated sampling of olfactory mucosa from primates. CC and KS helped in culturing stem cells and performing characterization. JS was involved in collecting olfactory mucosa from rats and JF from macaque. FSR, MK, AC, and PP were involved in drafting and revising the manuscript. MM coordinated biopsies from horses and dogs, revised the manuscript and helped in the design of the study. SDG conceived and designed the study, participated in cell cultures and carried out flow cytometry analysis, helped with data analysis and interpretation, and assisted in drafting the manuscript. All authors read and approved the final manuscript.

\section{Ethics approval and consent to participate}

Anesthesia and surgical procedures were performed according to the European law on Animal Care Guidelines and the Animal Care Committee of Aix-Marseille University and Ethic Committee of the Research Institute in Semiochemistry and Applied Ethology (C2EA125) approved our protocols. For client-owned animals, a written informed consent to participate was obtained through a specific authorization form

\section{Consent for publication}

Not applicable

\section{Competing interests}

The authors declare that they have no competing interests.

\section{Author details}

IRSEA, Research Institute in Semiochemistry and Applied Ethology, Quartier Salignan, 84400 Apt, France. ${ }^{2}$ Aix Marseille Univ, CNRS, NICN, Marseille, France. ${ }^{3}$ Inserm CBT 1409, Centre d'Investigations Cliniques en Biothérapie, Marseille, France. ${ }^{4}$ Département ORL, Hôpital Universitaire Nord, AP-HM, Marseille, France. ${ }^{5}$ Aix-Marseille Univ, IFSTTAR, LBA, Marseille, France. ${ }^{6}$ Centre Hospitalier Vétérinaire Pommery, 51100 Reims, France. ${ }^{7}$ Société Hippique Le frigouyé, 30650 Saze, France. ${ }^{8}$ Aix-Marseille Univ, CNRS, LPC, Marseille, France. ${ }^{9}$ Present address: Vect-Horus S.A.S., Faculté de Médecine Secteur Nord, CS80011, Boulevard Pierre Dramard, 13344 Marseille, Cedex 15, France.

Received: 12 April 2017 Accepted: 11 January 2018

Published online: 17 January 2018

\section{References}

1. Fortier LA, Travis AJ. Stem cells in veterinary medicine. Stem Cell Res Ther. 2011; https://doi.org/10.1186/scrt50.

2. Ribitsch I, Burk J, Delling U, et al. Basic science and clinical application of stem cells in veterinary medicine. Adv Biochem Eng Biotechnol. 2010;123:219-63.

3. Stoltz JF, de Isla N, Li YP, et al. Stem cells and regenerative medicine: myth or reality of the 21 th century. Stem Cells Int. 2015;2015:734731. https://doi. org/10.1155/2015/734731.

4. Kim SU, de Vellis J. Stem cell-based cell therapy in neurological diseases: a review. J Neurosci Res. 2009;87:2183-200.

5. Lindvall O, Kokaia Z. Stem cells for the treatment of neurological disorders. Nature. 2006:441:1094-6.

6. Garcia JM, Mendonca L, Brant R, et al. Stem cell therapy for retinal diseases. World J Stem Cells. 2015;7:160-4.

7. Matar AA, Chong JJ. Stem cell therapy for cardiac dysfunction. Spring. 2014; 3:440. https://doi.org/10.1186/2193-1801-3-440.

8. Volarevic V, Erceg S, Bhattacharya SS, et al. Stem cell-based therapy for spinal cord injury. Cell Transplant. 2013;22:1309-23.

9. Antonic A, Sena ES, Lees JS, et al. Stem cell transplantation in traumatic spinal cord injury: a systematic review and meta-analysis of animal studies. PLoS Biol. 2013;11(12):e1001738. https://doi.org/10.1371/journal.pbio.1001738.

10. Porada CD, Atala AJ, Almeida-Porada G. The hematopoietic system in the context of regenerative medicine. Methods. 2015;99:44-61. https://doi.org/ 10.1016/j.ymeth.2015.08.015.

11. Goncalves NN, Ambrosio CE, Piedrahita JA. Stem cells and regenerative medicine in domestic and companion animals: a multispecies perspective. Reprod Domest Anim. 2014;49(Suppl 4):2-10.

12. Lopez MJ, Jarazo J. State of the art: stem cells in equine regenerative medicine. Equine Vet J. 2015;47:145-54.

13. Murrell W, Feron F, Wetzig A, et al. Multipotent stem cells from adult olfactory mucosa. Dev Dyn. 2005;233:496-515.

14. Delorme B, Nivet E, Gaillard J, et al. The human nose harbors a niche of olfactory ectomesenchymal stem cells displaying neurogenic and osteogenic properties. Stem Cells Dev. 2010;19:853-66.

15. Tome M, Lindsay SL, Riddell JS, Barnett SC. Identification of nonepithelial multipotent cells in the embryonic olfactory mucosa. Stem Cells. 2009;27: 2196-208.

16. Mazzarella R, Garnica TK, Roballo K, Ambrosio CE. Células-tronco derivadas do epitélio olfatório: perspectivas terapêuticas na medicina veterinária. Pesq Vet Bras. 2016;36:787-92.

17. Boyd AS, Rodrigues NP, Lui KO, et al. Concise review: immune recognition of induced pluripotent stem cells. Stem Cells. 2012;30:797-803.

18. King NM, Perrin J. Ethical issues in stem cell research and therapy. Stem Cell Res Ther. 2014; https://doi.org/10.1186/scrt474.

19. Somoza RA, Rubio FJ. Cell therapy using induced pluripotent stem cells or somatic stem cells: this is the question. Curr Stem Cell Res Ther. 2012;7:191-6.

20. Girard SD, Deveze A, Nivet $E$, et al. Isolating nasal olfactory stem cells from rodents or humans. J Vis Exp. 2011; https://doi.org/10.3791/2762.

21. Forni PE, Wray S. Neural crest and olfactory system: new prospective. Mol Neurobiol. 2012;46:349-60.

22. Lindsay SL, Riddell JS, Barnett SC. Olfactory mucosa for transplant-mediated repair: a complex tissue for a complex injury? Glia. 2010;58:125-34.

23. Kaltschmidt B, Kaltschmidt C, Widera D. Adult craniofacial stem cells: sources and relation to the neural crest. Stem Cell Rev. 2012;8:658-71.

24. Shafiee A, Kabiri M, Ahmadbeigi N, et al. Nasal septum-derived multipotent progenitors: a potent source for stem cell-based regenerative medicine. Stem Cells Dev. 2011;20:2077-91. 
25. Nivet E, Vignes M, Girard SD, et al. Engraftment of human nasal olfactory stem cells restores neuroplasticity in mice with hippocampal lesions. J Clin Invest. 2011;121:2808-20.

26. Nivet E, Deveze A, Girard SD, et al. Nose at the bedside of the brain. Med Sci (Paris). 2011;27:932-4.

27. McDonald C, Mackay-Sim A, Crane D, Murrell W. Could cells from your nose fix your heart? Transplantation of olfactory stem cells in a rat model of cardiac infarction. ScientificWorldJournal. 2010;10:422-33.

28. Toft A, Tome M, Lindsay SL, et al. Transplant-mediated repair properties of rat olfactory mucosal OM-I and OM-II sphere-forming cells. J Neurosci Res. 2012;90:619-31.

29. Xiao M, Klueber KM, Guo Z, et al. Human adult olfactory neural progenitors promote axotomized rubrospinal tract axonal reinnervation and locomotor recovery. Neurobiol Dis. 2007;26:363-74.

30. Xiao M, Klueber KM, Lu C, et al. Human adult olfactory neural progenitors rescue axotomized rodent rubrospinal neurons and promote functional recovery. Exp Neurol. 2005;194:12-30.

31. Pandit SR, Sullivan JM, Egger V, et al. Functional effects of adult human olfactory stem cells on early-onset sensorineural hearing loss. Stem Cells. 2011;29:670-7.

32. Murrell W, Wetzig A, Donnellan M, et al. Olfactory mucosa is a potential source for autologous stem cell therapy for Parkinson's disease. Stem Cells. 2008;26:2183-92

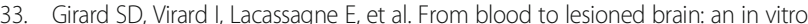
study on migration mechanisms of human nasal olfactory stem cells. Stem Cells Int. 2017;2017:1478606. https://doi.org/10.1155/2017/1478606.

34. Stamegna JC, Girard SD, Veron A, et al. A unique method for the isolation of nasal olfactory stem cells in living rats. Stem Cell Res. 2014;12:673-9.

35. Feron F, Perry C, Girard SD, Mackay-Sim A. Isolation of adult stem cells from the human olfactory mucosa. Methods Mol Biol. 2013;1059:107-14.

36. Barsby T, Guest D. Transforming growth factor beta3 promotes tendon differentiation of equine embryo-derived stem cells. Tissue Eng Part A. 2013;19:2156-65.

37. Shen H, Gelberman RH, Silva MJ, et al. BMP12 induces tenogenic differentiation of adipose-derived stromal cells. PLoS One. 2013; https://doi.org/10.1371/ journal.pone.0077613.

38. Tan SL, Ahmad RE, Ahmad TS, et al. Effect of growth differentiation factor 5 on the proliferation and tenogenic differentiation potential of human mesenchymal stem cells in vitro. Cells Tissues Organs. 2012;196:325-38.

39. Hillmann A, Ahrberg AB, Brehm W, et al. Comparative characterization of human and equine mesenchymal stromal cells: a basis for translational studies in the equine model. Cell Transplant. 2016;25:109-24.

40. Ranera B, Barry F. A horse of a different color. Cytometry A. 2014;85:658-9.

41. De Schauwer C, Piepers S, Van de Walle GR, et al. Search for cross-reactivity to immunophenotype equine mesenchymal stromal cells by multicolor flow cytometry. Cytometry A. 2012;81:312-23.

42. Tan SL, Ahmad TS, Selvaratnam L, Kamarul T. Isolation, characterization and the multi-lineage differentiation potential of rabbit bone marrow-derived mesenchymal stem cells. J Anat. 2013;222:437-50.

43. Semyari $H$, Rajipour M, Bastami F, Semyari $H$. Isolation and culture of mesenchymal stem cells from rabbit scapular subcutaneous adipose tissue and their ability to differentiate into osteoblasts. Avicenna Journal of Dental Research. 2015; https://doi.org/10.17795/ajdr-22308.

44. Lee TC, Lee $\mathrm{TH}$, Huang $\mathrm{YH}$, et al. Comparison of surface markers between human and rabbit mesenchymal stem cells. PLoS One. 2014; https://doi.org/ 10.1371/journal.pone.0111390.

45. Ercolin AC, Roballo KC, Casals JB, et al. Rabbit olfactory stem cells. Isolation protocol and characterization. Acta Cir Bras. 2016;31:59-66.

46. Murrell W, Sanford E, Anderberg L, et al. Olfactory stem cells can be induced to express chondrogenic phenotype in a rat intervertebral disc injury model. Spine J. 2009;9:585-94.

47. Duan D, Olfactory LM. Mucosa: a rich source of cell therapy for central nervous system repair. Rev Neurosci. 2015;26:281-93.

48. Barberini DJ, Freitas NP, Magnoni MS, et al. Equine mesenchymal stem cells from bone marrow, adipose tissue and umbilical cord: immunophenotypic characterization and differentiation potential. Stem Cell Res Ther. 2014;5:25-35.

49. Bertolo A, Steffen F, Malonzo-Marty C, Stoyanov J. Canine mesenchymal stem cell potential and the importance of dog breed - implication for cellbased therapies. Cell Transplant. 2015;24:1969-80.

50. De Ugarte DA, Morizono K, Elbarbary A, et al. Comparison of multi-lineage cells from human adipose tissue and bone marrow. Cells Tissues Organs. 2003;174:101-9.
51. Nishimori M, Yamada Y, Hoshi K, et al. Health-related quality of life of unrelated bone marrow donors in Japan. Blood. 2002:99:1995-2001.

52. Schaffler A, Buchler C. Concise review: adipose tissue-derived stromal cellsbasic and clinical implications for novel cell-based therapies. Stem Cells. 2007:25:818-27.

53. Schipper BM, Marra KG, Zhang W, et al. Regional anatomic and age effects on cell function of human adipose-derived stem cells. Ann Plast Surg. 2008. 60:538-44.

54. de Girolamo L, Lopa S, Arrigoni E, et al. Human adipose-derived stem cells isolated from young and elderly women: their differentiation potential and scaffold interaction during in vitro osteoblastic differentiation. Cytotherapy. 2009; 11:793-803.

55. Zhu M, Kohan E, Bradley J, et al. The effect of age on osteogenic, adipogenic and proliferative potential of female adipose-derived stem cells. J Tissue Eng Regen Med. 2009:3:290-301.

56. Rui K, Zhang Z, Tian J, et al. Olfactory ecto-mesenchymal stem cells possess immunoregulatory function and suppress autoimmune arthritis. Cell Mol Immunol. 2015;13:401-8.

57. Pastides PS, Welck MJ, Khan WS. Use of bone marrow derived stem cells in trauma and orthopaedics: a review of current concepts. World J Orthop. 2015;6:462-8.

58. Bauge C, Boumediene K. Use of adult stem cells for cartilage tissue engineering: current status and future developments. Stem Cells Int. 2015; https://doi.org/10. $1155 / 2015 / 438026$

59. Rothrauff BB, Tuan RS. Cellular therapy in bone-tendon interface regeneration. Organ. 2014;10:13-28.

60. Centeno CJ. Clinical challenges and opportunities of mesenchymal stem cells in musculoskeletal medicine. PM R. 2014;6:70-7.

61. Bons N, Rieger F, Prudhomme D, et al. Microcebus Murinus: a useful primate model for human cerebral aging and Alzheimer's disease? Genes Brain Behav. 2006:5:120-30.

62. Gonzalez-Martinez A, Rosado B, Pesini P, et al. Plasma beta-amyloid peptides in canine aging and cognitive dysfunction as a model of Alzheimer's disease. Exp Gerontol. 2011;46:590-6.

63. Landsberg GM, Nichol J, Araujo JA. Cognitive dysfunction syndrome: a disease of canine and feline brain aging. Vet Clin North Am Small Anim Pract. 2012:42:749-68.

64. Schopf C, Zimmermann E, Tunsmeyer J, et al. Hearing and age-related changes in the gray mouse lemur. J Assoc Res Otolaryngol. 2014;15:993-1005.

65. Waguespack R, Hanson RR. Navicular syndrome in equine patients anatomy, causes, and diagnosis. Compend Contin Educ Vet. 2010;32:E7.

66. Brommer $\mathrm{H}$, van Weeren PR, Brama PA. New approach for quantitative assessment of articular cartilage degeneration in horses with osteoarthritis. Am J Vet Res. 2003;64:83-7.

67. Mackay-Sim A, Feron F, Cochrane J, et al. Autologous olfactory ensheathing cell transplantation in human paraplegia: a 3-year clinical trial. Brain. 2008; 131:2376-86.

68. Feron F, Perry C, Cochrane J, et al. Autologous olfactory ensheathing cell transplantation in human spinal cord injury. Brain. 2005;128:2951-60.

69. Barraud P, Seferiadis AA, Tyson LD, et al. Neural crest origin of olfactory ensheathing glia. Proc Natl Acad Sci U S A. 2010;107:21040-5.

70. Witheford M, Westendorf K, Roskams AJ. Olfactory ensheathing cells promote corticospinal axonal outgrowth by a L1 CAM-dependent mechanism. Glia. 2013;61:1873-89.

71. Liu SJ, Zou Y, Belegu V, et al. Co-grafting of neural stem cells with olfactory en sheathing cells promotes neuronal restoration in traumatic brain injury with an anti-inflammatory mechanism. J Neuroinflammation. 2014;11:66. 